Article

\title{
Frequency Conversion in KTP Crystal and Its Isomorphs
}

\author{
Sergey Gagarskiy ${ }^{1}$, Sergey Grechin ${ }^{2,3, *}$, Pioter Druzhinin ${ }^{1}{ }^{\circledR}$, Kiyoshi Kato ${ }^{4,5, *}$, \\ David Kochiev ${ }^{3}$, Pavel Nikolaev ${ }^{2} \mathbb{D}$ and Nobihuro Umemura ${ }^{4, *}$ \\ 1 School of Photonics, ITMO University, Kronverkskiy Prospekt, 49, 197101 Sankt-Peterburg, Russia; \\ s.gagarsky@mail.ru (S.G.); pioter.druzhinin@yandex.ru (P.D.) \\ 2 LLC Neophotonics, Obukhov Defense Avenue, 21, 192019 Sankt-Peterburg, Russia; paneeque@gmail.com \\ 3 Prokhorov General Physics Institute of the Russian Academy of Sciences, Vavilov Street 38, 119991 Moscow, \\ Russia;dkochiev@gmail.com \\ 4 Chitose Institute of Science and Technology, Chitose, Hokkaido 066-0012, Japan \\ 5 Okamoto Optics Works, Inc., Haramachi Isogo-ku, Yokohama 235-0008, Japan \\ * Correspondence: gera@bmstu.ru (S.G.); nlocrystal@gmail.com (K.K.); umemura@photon.chitose.ac.jp (N.U.)
}

Received: 16 July 2018; Accepted: 29 September 2018; Published: 10 October 2018

\begin{abstract}
We report the results of an analysis of the functional capabilities of the KTP crystal and its isomorphs for nonlinear-optical frequency conversion of all types of interactions in the transparency range of the crystal. The possibility of implementing angle, wavelength (frequency), and temperature-noncritical phase matching is shown.
\end{abstract}

Keywords: nonlinear crystals; KTP and isomorphs; frequency conversion; functional capabilities; temperature-noncritical mode

\section{Introduction}

Since the first publication of the data on the synthesis of the KTP crystal (potassium titanyl phosphate, $\mathrm{KTiOPO}_{4}$ ) [1] and of the results of measuring its characteristics, it became evident that the crystal would take its rightful place for frequency conversion tasks and has fully justified these hopes [2-5].

The synthesis of this crystal stimulated the study of the possibility of creating isomorphic media with a $\mathrm{MTiOXO}_{4}$ structure, where $\left\{\mathrm{M}=\mathrm{NH}_{4}, \mathrm{~K}, \mathrm{Rb}, \mathrm{TI}\right.$, and $\left.\mathrm{Cs}\right\}$ and $\{\mathrm{X}=\mathrm{P}$ and As $\}$ [6-17]. A large amount of work has been done, and new crystals have been synthesized including KTA (potassium titanyl arsenate, $\mathrm{KTiOAsO}_{4}$ ), RTA (rubidium titanyl arsenate, $\mathrm{RbTiOAsO}_{4}$ ), $\mathrm{RTP}$ (rubidium titanyl phosphate, $\mathrm{RbTiOPO}_{4}$ ), and CTA (cesium titanyl arsenate, $\mathrm{CsTiOAsO}_{4}$ ). Each of them has their own fields of application. Additionally, it is possible to note the works on the synthesis and investigation of such crystals as $\mathrm{KNaTP}\left(\mathrm{K}_{1-\mathrm{x}} \mathrm{Na}_{\mathrm{x}} \mathrm{TiOPO}_{4}\right)$, KNTA $\left(\mathrm{K}_{1-\mathrm{x}}\left(\mathrm{NH}_{4}\right)_{\mathrm{x}} \mathrm{TiOAsO}_{4}\right)$, $\operatorname{KGTP}\left(\mathrm{KTi}_{1-x} \mathrm{Ga}_{\mathrm{x}} \mathrm{O}_{1-\mathrm{x}} \mathrm{PO}_{4}(\mathrm{~F}, \mathrm{OH})_{\mathrm{x}}\right)$, AKTP $\left(\mathrm{Ag}_{0.85} \mathrm{~K}_{0.15} \mathrm{TiOPO}_{4}\right)$, NHTP $\left(\left(\mathrm{NH}_{4}\right)_{0.5} \mathrm{H}_{0.5} \mathrm{TiOPO}_{4}\right)$ [18], and crystals activated by ions of rare-earth elements [19-21].

For a certain but rather wide range of tasks, these crystals have no alternative. They have a high effective nonlinearity coefficient $\left(d_{\text {eff }}\right)$, rather large values of all the phase-matching widths, and of the thermal conductivity coefficient, good optical quality, small absorption, and linear expansion coefficients, as well as non-hygroscopicity. Besides, they are inexpensive in manufacture. Not very high value of the damage threshold determines the field of the most effective applications of these crystals, which includes generation of harmonics and parametric frequency conversion in the near-IR range. In these crystals, noncritical processes were realized for all parameters, i.e., angles, wavelength, and temperature. Moreover, the possibility of producing periodically and non-periodically poled 
structures in them at record high values of the nonlinear susceptibility coefficient $d_{33}$ allowed them to find wide application for the problems of frequency conversion of low-intensity radiation in the crystal transparency range [22-25].

In addition to frequency conversion, these crystals are used as modulators and $Q$-switches [26,27]. Work is underway to design fibers and waveguide structures [28-37], photonic structures [38-40] from these media. Additionally, these crystals are very promising for the generation of THz radiation [41-45].

To date, a large number of reviews on these crystals have been published. It is impossible to enumerate all the problems on the generation of radiation at different wavelengths in the KTP crystal and its isomorphs, which were obtained experimentally. Nevertheless, not all their capabilities are fully defined. In this paper, we present the results of an analysis of the functional capabilities of the KTP crystal and its isomorphs for all frequency conversion tasks including generation of harmonics and sum and difference frequencies, as well as parametric generation in the range of their transparency $(0.4-5.0 \mu \mathrm{m})$.

The KTP crystal and its isomorphs belong to $m m 2$ point-group symmetry, with the mutual orientation of the axes XYZ-abc. A common property of these crystals is that the signs of the nonlinear susceptibility tensor coefficients $d_{\mathrm{ij}}$ are identical (in contrast to the crystals of point group $3 m$ ), and their values differ insignificantly. This leads to the fact that the distributions of the effective nonlinearity coefficients have practically the same form. Figure 1 shows the distributions of the effective nonlinearity coefficients $d_{\text {eff }}$ in the KTP crystal for two types of interactions, ssf and $f s f=s f f$ (s-slow, $f$-fast) in accordance to equations from Reference [46]. The lines of white color show the phase-matching directions for the second harmonic generation (SHG), i.e., ssf (SHG at $\lambda_{1}=\lambda_{2}=3.4 \mu \mathrm{m}$, for which the value $d_{\text {eff }}$ is maximal) and $f s f=s f f$ (SHG at $\lambda_{1}=\lambda_{2}=1.064 \mu \mathrm{m}$, as widely used). For a large number of applications, a cut of the crystal is selected on the phase-matching curve, for which $d_{\text {eff }}$ has a maximum value. For the particular cases of ssf type shown in Figure 1, this value of $d_{\mathrm{eff}}$ is $0.65 \mathrm{pm} / \mathrm{V}$ at $\varphi=42^{\circ}$ and $\theta=49.7^{\circ}$, and for the cases of $f s f=$ sff type we have $d_{\mathrm{eff}}=3.42 \mathrm{pm} / \mathrm{V}$ at $\varphi=23.5^{\circ}$ and $\theta=90^{\circ}$. Black points at Figure 1 show these directions. The maximum value $d_{\text {eff }}$ takes place for the second type of phase matching, i.e., $s f f=f s f$, which is most widely used in practice.

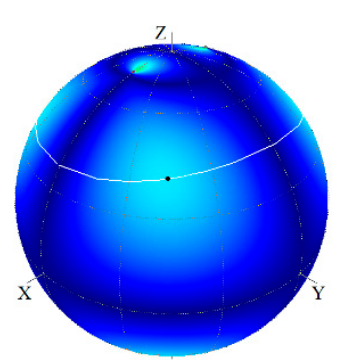

(a) $s s f$

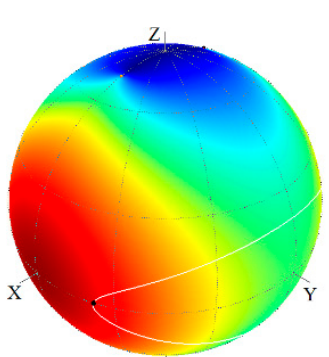

(b) $f s f=s f f$

Figure 1. Distribution of $d_{\mathrm{eff}}(\varphi, \theta)$ and phase-matching directions for SHG in KTP crystal: (a) ssf-, and (b) $s f f=f s f$ types of interactions.

Let us consider the functional possibilities of frequency conversion for all possible processes and types of phase matching in the crystal transparency range.

\section{General Features of Frequency Conversion}

The method of analysis of the functional possibilities of the KTP crystal and its isomorphs proposed in References [47,48] uses the form of presentation for the crystal figure-of-merit FOM $=d_{\text {eff }}^{2} /\left(n_{1} n_{2} n_{3}\right)$ from the wavelengths $\lambda_{1}$ and $\lambda_{2}$ for uniaxial [47] and biaxial [48] crystals. Hereafter, the relation $\lambda_{1} \geq \lambda_{2}>\lambda_{3}$ is adopted. For all the values of the wavelengths $\lambda_{1}$ and $\lambda_{2}$, the value of $\lambda_{3}\left(1 / \lambda_{3}=1 / \lambda_{1}+1 / \lambda_{2}\right)$ is uniquely determined, the plots of the dependences for which are given for all the results presented below. For each pair of wavelengths $\lambda_{1}$ and $\lambda_{2}$, a cone of phase-matching directions was calculated. Along these directions, there was one defined for which $d_{\text {eff }}$ 
has a maximum value. It was used to calculate $F_{D} M_{D}\left(\lambda_{1}, \lambda_{2}\right)$, each value of which on the distributions presented below in Figures 2, 4, 6-10, 12-17 has its color from the right-hand palette. Here, the parameter $F O M_{\mathrm{D}}\left(\lambda_{1}, \lambda_{2}\right)$ corresponds to the maximum value $d_{\text {eff }}$ on the phase-matching curve, unlike the other FOM parameter defined below in Section 3. In all the figures of the FOM $\left(\lambda_{1}, \lambda_{2}\right)$ distributions the maximum values are shown. The following data (Sellmeier equations for indices of refractions, $d n_{\mathrm{i}} / d \mathrm{~T}$ and $d_{\mathrm{ij}}$ coefficients) were used for the crystal parameters: KTP [49,50], RTP [51], RTA [52], KTA [53], and CTA [54,55]. There is one peculiarity here. All this group of crystals is grown by different technologies [56-63], in different regimes and with different composition of the initial charge. This leads to the fact that the crystals have different refractive indices. As a result, the phase-matching angles can differ by a few degrees. The data [49-53] used in the calculations most closely correspond to the crystals supplied by the majority of manufacturers. Below, we will show the difference between the results for FOM $\left(\lambda_{1}, \lambda_{2}\right)$ using various optical and thermo-optical parameters of the KTP crystal.

It is known (see, e.g., $[63,64]$ ) that the coefficients of the nonlinear susceptibility tensor $d_{\mathrm{ijk}}$ are characterized by dispersion. However, due to the lack of complete data for all crystals, dispersion was not taken into account in the calculations. We used typical values [46] in the crystal transparency range. The variation in the values of $d_{\mathrm{ijk}}$ in this range does not change the general character of the distributions.

Figure 2 shows the FOM $\left(\lambda_{1}, \lambda_{2}\right)$ distributions for the wavelengths $\lambda_{1}$ and $\lambda_{2}$ for all types of interactions for the KTP crystal in its transparency range (the boundaries of the range are shown by external dashed lines). For the used ratio of wavelengths $\lambda_{\mathrm{i}}$, the results appear below the diagonal of the graph. It is easy to see that for ssf-type interaction the distribution is symmetric with respect to the diagonal. For $s f f$ and $f s f$ types, the results are mutually complementary with respect to the diagonal. Black color lines correspond to $\lambda_{3}\left(1 / \lambda_{1}+1 / \lambda_{2}=1 / \lambda_{3}\right)$.

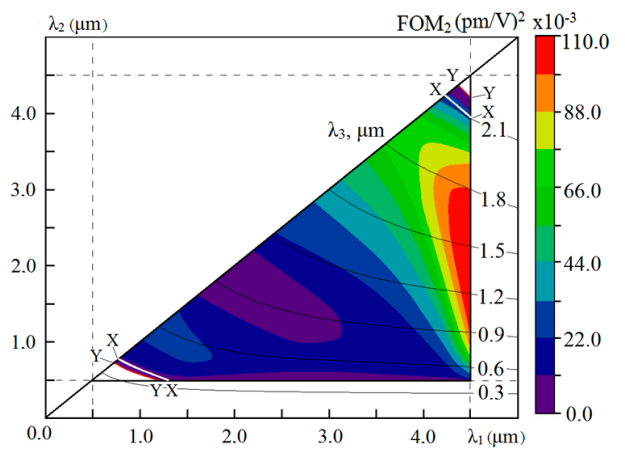

(a) $s s f$

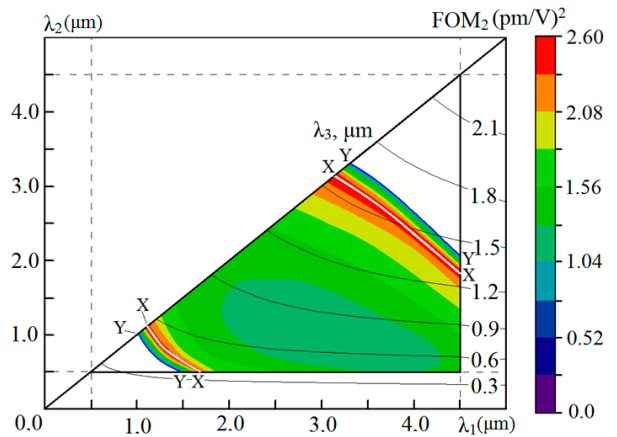

(b) $f s f$

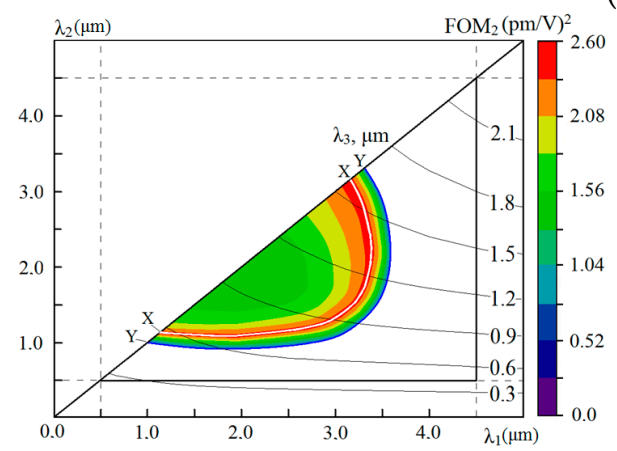

(c) $s f f$

Figure 2. $F_{\mathrm{D}}\left(\lambda_{1}, \lambda_{2}\right)$ distributions for KTP crystal for all types of interactions: (a) $s s f$, (b) $f s f$, (c) $s f f$.

Almost throughout the crystal transparency range, phase matching is realized for the first and second types of interactions. The boundary of the $F O M_{D}\left(\lambda_{1}, \lambda_{2}\right)$ distribution determines combinations of wavelengths at which angular noncritical phase matching takes place. This is most fully obvious 
for the sff type of interaction in Figure 2. For all crystals of the KTP group, phase matching with a change in wavelength appears and disappears along the $y$ axis [65]. In this case, it is noncritical in angles $\varphi$ and $\theta$. In all the figures, a combination of wavelengths for which phase matching exists along the $x$ axis is shown by the white line. For SHG, this is realized at $\lambda_{1}=\lambda_{2}=1.078 \mu \mathrm{m}$ and $\lambda_{1}=$ $\lambda_{2}=3.18 \mu \mathrm{m}$. This is also angular noncritical phase matching. For type-II phase matching along the $x$ axis, the coefficient $d_{\text {eff }}$ has a maximum value. Thus, at all combinations of wavelengths with phase matching along the $x$ axis, the maximum conversion efficiency can be obtained.

For this group of crystals, phase matching along the $z$ axis is absent. In the KTP crystal, the maximum value of the wavelength for the sum frequency generation is possible with type-II phase matching for SHG at $\lambda_{1}=\lambda_{2}=3.308 \mu \mathrm{m}$, whereas the minimum value of the wavelength for SHG is observed at $\lambda_{1}=\lambda_{2}=0.994 \mu \mathrm{m}$. The minimum value of the wavelength with ssf- and $f s f$-type interactions can be obtained by sum frequency generation (SFG) at the boundary of the transparency range.

The character of the $F O M_{\mathrm{D}}\left(\lambda_{1}, \lambda_{2}\right)$ distribution for the ssf type in the main part of the wavelength region of the transparency range is determined by the fact that the terms with different elements of the tensor $d_{\mathrm{ij}}$ with opposite signs contribute to the nonlinear polarizability of the medium. For a value of $\lambda_{1}$ at the boundary of the transparency range, a large variance for the angle of the optical axis $V_{z}(\lambda)$, a large difference $\mathrm{V}_{\mathrm{z}}\left(\lambda_{1}\right)-\mathrm{V}_{\mathrm{z}}\left(\lambda_{2}\right)$, leads to an increase in the values of $d_{\text {eff. }}$. But even in this region the maximum value of $F O M_{\mathrm{D}}\left(\lambda_{1}, \lambda_{2}\right)$ for the ssf type is less than that for $f s f$ and $s f f$ types, the region of phase matching for ssf type being maximal.

The presented results allow us to determine the possible tuning range of optical parametric oscillators. For a given value of $\lambda_{3}$, the phase matching region shows the tuning range for $\lambda_{1}$ and $\lambda_{2}$.

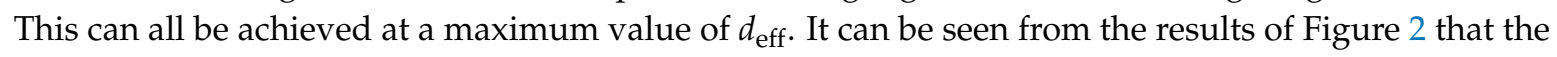
largest tuning range can be obtained by changing the phase-matching angle in the $x z$ plane.

The maximum pump wavelength for KTP is $1.7 \mu \mathrm{m}$. The largest tuning range can be obtained for $\lambda_{3}=0.8-1.2 \mu \mathrm{m}$. In this case, the wavelength range is $\lambda_{1}=1.1-4.5 \mu \mathrm{m}$. This can all be achieved at a maximum value of $d_{\text {eff }}$ in the $x y$ plane, since the value of $F O M_{D}\left(\lambda_{1}, \lambda_{2}\right)$ is determined for these values.

The method of analysis proposed in References [47,48] allows us to determine combinations of wavelengths at which the regime of frequency-noncritical phase matching (FNCPM) is realized. The condition $d \Delta k / d \lambda=0$ corresponds to it. Figure 3 shows the wavelength dependence of the phase-matching angle $\theta_{\mathrm{phm}}$ and the coefficient $d_{\mathrm{eff}}$ in the $x z$ plane for the SHG with the type-II interaction in the KTP crystal. One can see that these dependences exhibit a consistent variation of these parameters. In this case, the FNCPM regime can be determined by the equality $d \theta / d \lambda=0$. Consequently, the minimum value of $F O M_{\mathrm{D}}\left(\lambda_{1}, \lambda_{2}\right)$ for the KTP crystal on the straight line representing SHG (Figure 2) corresponds to the FNCPM regime.

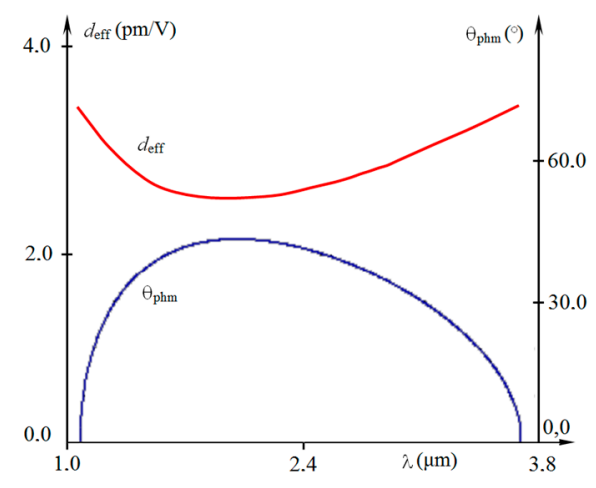

Figure 3. Distributions of phase-matching angle $\theta$ and $d_{\text {eff }}$ coefficient versus wavelength for SHG in KTP crystal with $(s f f)=(f s f)$ type of interaction. 
Similarly, the combination of the wavelengths $\lambda_{1}$ and $\lambda_{2}$ for FNCPM can be determined for all the frequency conversion processes, i.e., generation of the third (THG), fourth (FoHG), fifth (FiHG) harmonics, and SFG (in Figure 4 they are indicated by the red line). In the FNCPM regime, the minimum values of $F O M_{\mathrm{D}}\left(\lambda_{1}, \lambda_{2}\right)$ along the straight line will correspond to the above frequency conversion processes. For fsf and sff interactions types in Figure 4, the dashed lines show the combination of $\lambda_{1}$ and $\lambda_{2}$ of the FNCPM regime. It should also be noted that FNCPM takes place for the combinations of the wavelengths $\lambda_{1}$ and $\lambda_{2}$ on all these lines, which are tangent to the isolines of the $F O M_{\mathrm{D}}\left(\lambda_{1}, \lambda_{2}\right)$ distributions. The FNCPM regime is realized accurately for the given ratio of the wavelengths. In addition, it can also be obtained in the vicinity of these values of $\lambda_{1}$ and $\lambda_{2}$ on the phase-matching curve [66], but at a smaller value of $d_{\text {eff. }}$ The dash-dotted line in Figure 4 shows the combinations of the wavelengths for the FNCPM regime in the $y z$ plane, which occurs in the KTP crystal and its isomorphs.

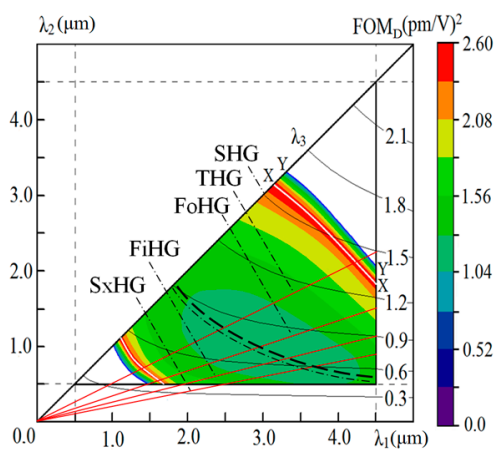

(a) $f s f$

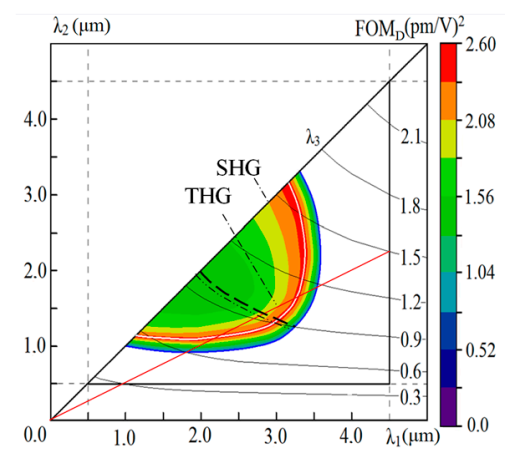

(b) $s f f$

Figure 4. Distributions FOM $\left(\lambda_{1}, \lambda_{2}\right)$ for KTP crystal with FNCPM.

The general character of the change in $F O M_{D}\left(\lambda_{1}, \lambda_{2}\right)$ also shows the ratio of the spectral widths of phase matching at various combinations of $\lambda_{1}$ and $\lambda_{2}$. Figure 4 a shows that, for example, for SHG, the rate of change in the value of $F O M_{D}\left(\lambda_{1}, \lambda_{2}\right)$ in the short-wave region is much larger than that in the long-wavelength region. A small rate of change in $F_{D}\left(\lambda_{1}, \lambda_{2}\right)$ corresponds to a slow change in the phase-matching angle $\theta_{\mathrm{phm}}$. In this case, the spectral width of phase matching in the long-wavelength region is greater than that in the short-wavelength region. This is confirmed by with the calculated wavelength dependences of the spectral width of phase matching for SHG in the KTP crystal (Figure 5): $0.6 \mathrm{~nm} \cdot \mathrm{cm}$ in short-wavelength region, and $7.2 \mathrm{~nm} \cdot \mathrm{cm}$ in the long-wavelength region. They differ by more than an order of magnitude.

The FNCPM regime is also possible when the frequency of ultra-short pulses is converted into a field of quasi-continuous wave (quasi-CW) radiation. Figure 6 shows the special case of the $F O M_{D}\left(\lambda_{1}\right.$, $\lambda_{2}$ ) distribution for sum frequency generation for type-II phase matching with broadband radiation at $\lambda_{1}=2.4 \mu \mathrm{m}$ and quasi-CW radiation at $\lambda_{2}=1.75 \mu \mathrm{m}$. In this case, the spectral width of phase matching with respect to $\lambda_{1}$ is $170 \mathrm{~nm} \cdot \mathrm{cm}^{1 / 2}$. This possibility follows from the fact that in the case when the tangent to the isolines of the FOM $\left(\lambda_{1}, \lambda_{2}\right)$ distribution is parallel to the axis, the value of $d_{\text {eff }}$ does not change in a wide range of the wavelengths. Taking into account the results of Figure 2, we find that in a wide range of the wavelengths, the phase-matching angle preserves its value. For the KTP crystal, for example, in the $x z$ plane, this is the angle $\theta_{\mathrm{phm}}$. The character of the $F O M_{\mathrm{D}}\left(\lambda_{1}, \lambda_{2}\right)$ distribution with a minimal value in the central region (Figure 6) shows that the FNCPM is possible in a wide range of the wavelengths. Additionally, possible is the FNCPM regime with a different ratio of the spectral widths of two wavelengths $\lambda_{1}$ and $\lambda_{2}$.

Figures 7-10 show the results for RTP (Figure 7), KTA (Figure 8), RTA (Figure 9), and CTA (Figure 10) crystals, which are similar to those in Figure 2 for KTP. 


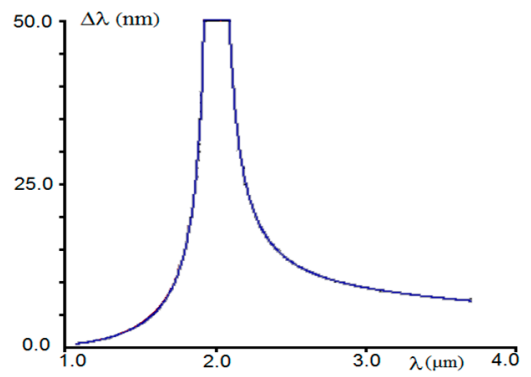

Figure 5. Dependence of spectral width versus wavelength for SHG in $x y$ plane.

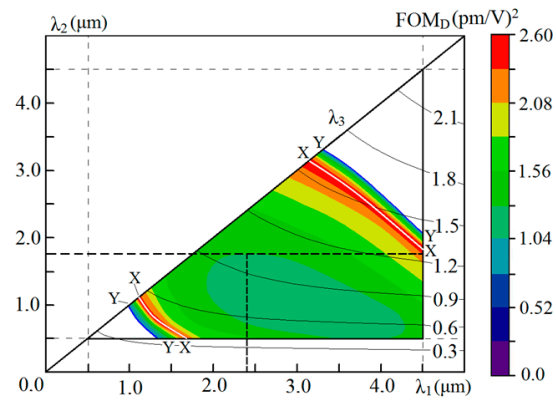

Figure 6. Distributions FOM $\left(\lambda_{1}, \lambda_{2}\right)$ for KTP crystal with FNCPM for pulse with $\lambda_{1}$.

In general, the character of the distributions for all these crystals is similar to that for KTP. As in the case of KTP, for the ssf type, phase matching exists almost everywhere in the crystal transparency range. However, the value of $d_{\text {eff }}$ for it is significantly less than that for $f s f$ and sff types. For the $f s f$ type, phase matching is realized in most of the crystal transparency range.

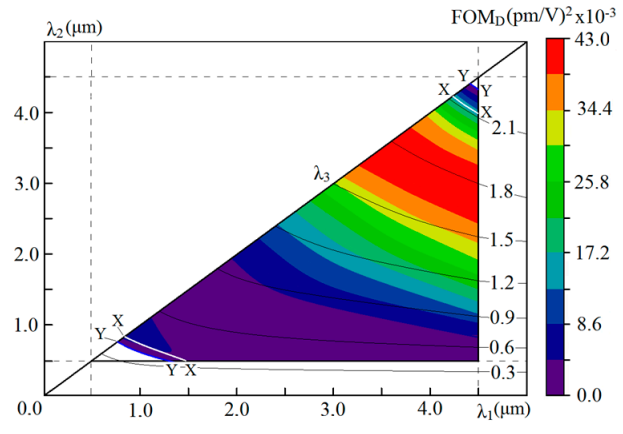

(a) $s s f$

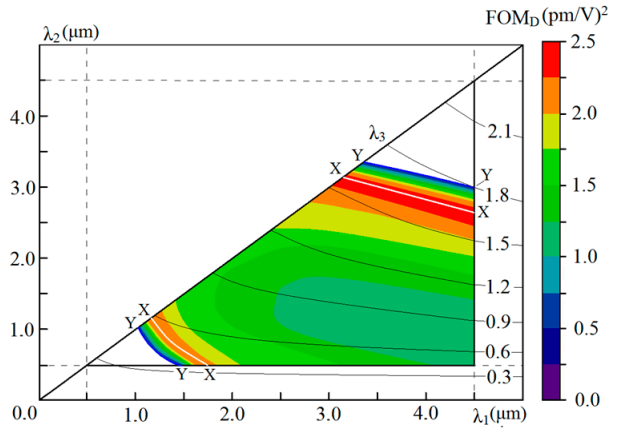

(b) $f_{s} f$

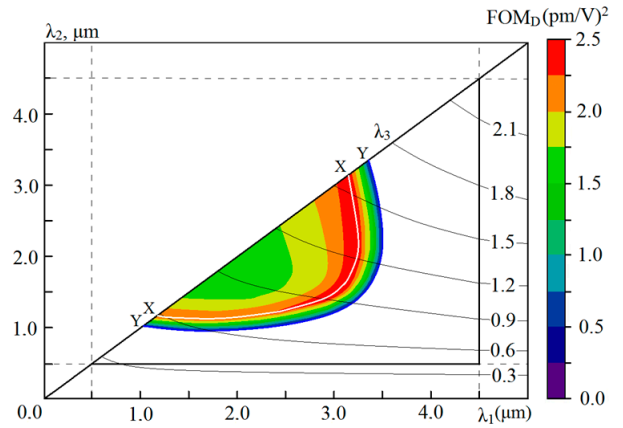

(c) $\mathrm{sff}$

Figure 7. $\operatorname{FOM}_{\mathrm{D}}\left(\lambda_{1}, \lambda_{2}\right)$ distributions for RTP crystal for all types of interactions: (a) $s s f,(\mathbf{b}) f_{s f}$, (c) $s f f$. 


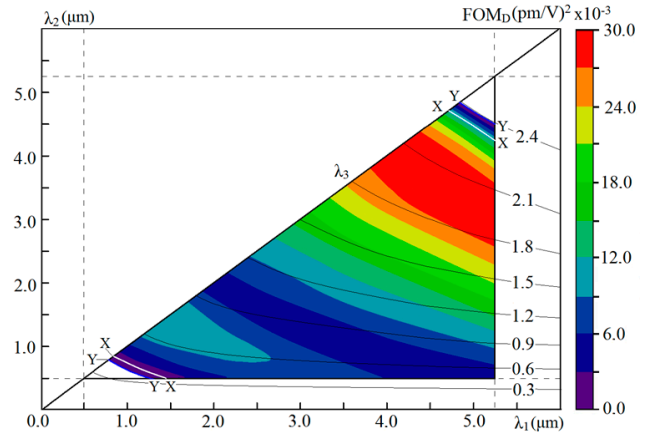

(a) $s s f$

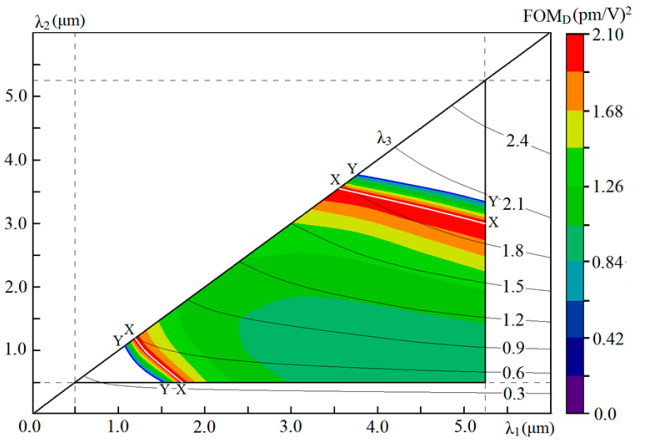

(b) $f s f$

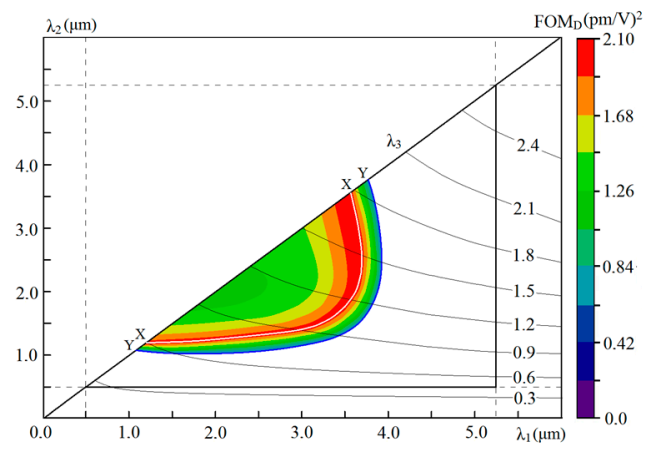

(c) $s f f$

Figure 8. $F O M_{\mathrm{D}}\left(\lambda_{1}, \lambda_{2}\right)$ distributions for KTA crystal for all types of interactions: (a) ssf, (b) $f s f$, (c) sff.

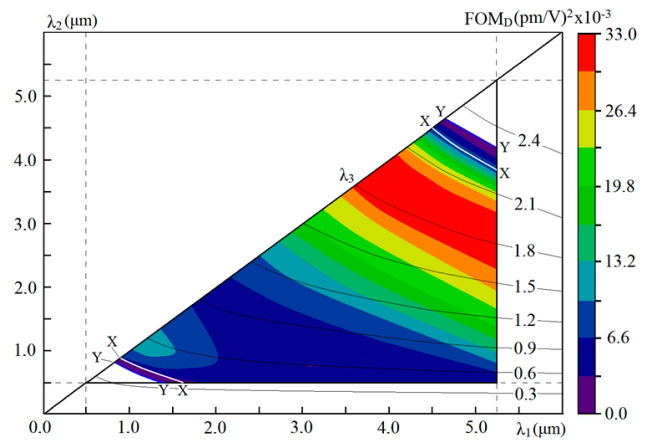

(a) $s s f$

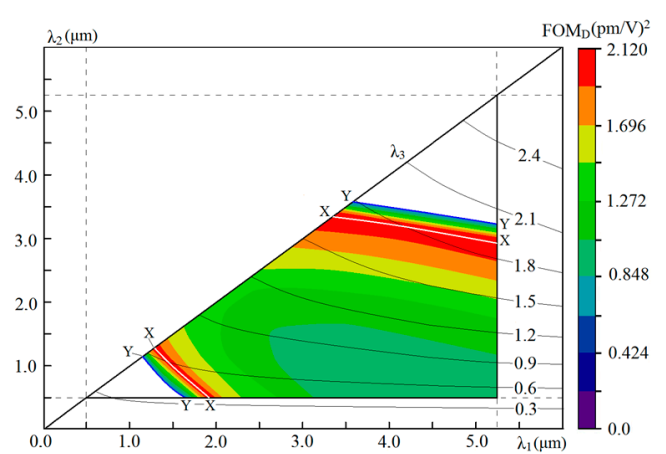

(b) $f s f$

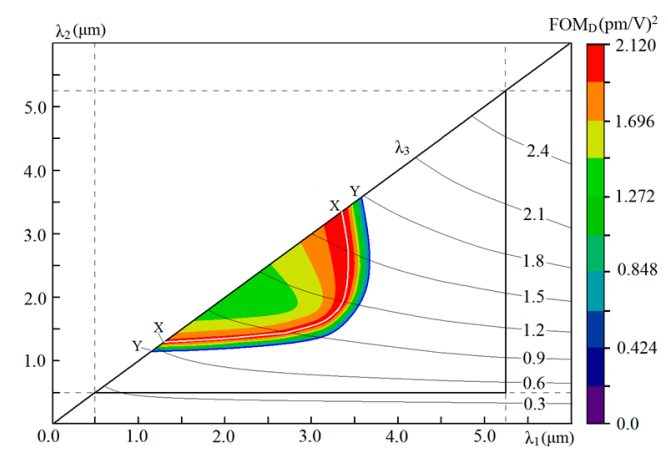

(c) $s f f$

Figure 9. $F O M_{\mathrm{D}}\left(\lambda_{1}, \lambda_{2}\right)$ distributions for RTA crystal for all types of interactions: (a) $s s f$, (b) $f s f$, (c) $s f f$. 


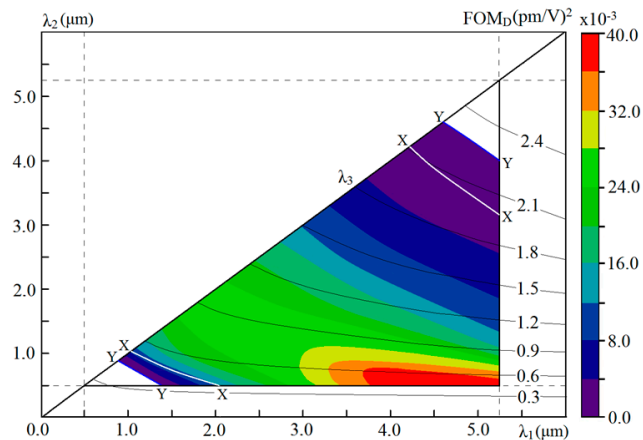

(a) $s s f$

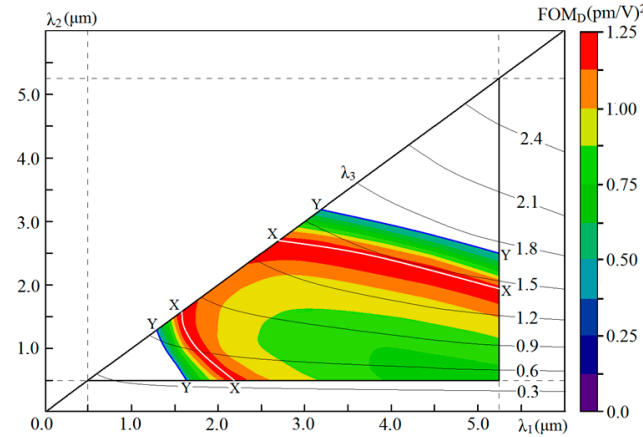

(b) $f s f$

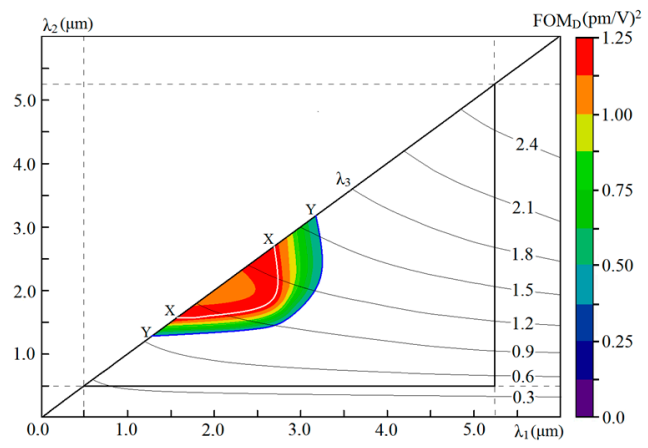

(c) sff

Figure 10. $F O M_{\mathrm{D}}\left(\lambda_{1}, \lambda_{2}\right)$ distributions for CTA crystal for all types of interactions: (a) $s s f$, (b) $f s f$, (c) $s f f$.

In the case of the CTA crystal, in the vicinity of the $x$ axis the rate of change in $F O M_{D}\left(\lambda_{1}, \lambda_{2}\right)$ in the complete wavelengths range is much less than that for other crystals. This corresponds to the fact that the spectral width of phase matching for CTA is larger. At a wavelength of $1.548 \mu \mathrm{m}$, the spectral width in CTA is $4.3 \mathrm{~nm} \cdot \mathrm{cm}$, whereas the spectral width in KTP at $1.076 \mu \mathrm{m}$ is $0.6 \mathrm{~nm} \cdot \mathrm{cm}$. In all crystals, the FNCPM regime can be obtained both for the generation of harmonics and sum and difference frequencies.

\section{Temperature-Noncritical Processes of Frequency Conversion}

The above results in the form of $F O M_{D}\left(\lambda_{1}, \lambda_{2}\right)$ distributions allow us to determine combinations of the wavelengths for which $d_{\text {eff }}$ has a maximum value and for which angle and frequency-noncritical phase matching takes place. It is also possible to implement temperature-noncritical phase matching (TNCPM) by determining the value of $F O M_{\mathrm{T}}\left(\lambda_{1}, \lambda_{2}\right)$ on the phase-matching cone along the directions for which $d \Delta k / d \mathrm{~T}=0$. This regime of frequency conversion in the KTP crystal has been repeatedly obtained by various authors [67-73]. As in the case of angle and frequency-noncritical phase matching, the first-order derivative with respect to temperature $d \Delta k / d \mathrm{~T}=0$ determines the TNCPM direction. The temperature width is determined by derivatives of a higher order.

It is important that the TNCPM direction is not strictly fixed in the crystal. It has dispersion as well as phase-matching and optical axis directions. To analyze the feasibility of the TNCPM regime and its dispersion, it was proposed [73] to determine the directions (cone) of temperature-noncritical interactions (TNCIs) independently of the phase-matching condition for which $\Delta k(\varphi, \theta)=0$. These are the directions along which $d \Delta k(\varphi, \theta) / d \mathrm{~T}=0$, no matter if phase matching takes place or not. The intersection of the phase-matching and TNCI cones determines the direction of TNCPM, since in this direction $\Delta k(\varphi, \theta)$ and $d \Delta k(\varphi, \theta) / d \mathrm{~T}$ are simultaneously equal to zero. With changing the radiation wavelength, both cones (phase matching and TNCI) change, which leads to a change in the TNCPM direction. This shows that this regime takes place in a finite range of wavelengths for a given frequency conversion process. 
Figure 11 shows the angular dependences for phase matching and TNCI of $s s f$ and $f s f$ interactions types for SHG in the KTP crystal at different wavelengths. For the ssf-type interaction, the TNCPM regime is initially obtained at a wavelength of $\lambda_{1}=\lambda_{2}=0.747 \mu \mathrm{m}$ in the $x y$ plane $\left(\varphi=64^{\circ}, \theta=90^{\circ}\right)$. As the wavelength of the radiation increases, the direction of TNCPM changes, and the values of the angles $\varphi$ and $\theta$ change. At a wavelength of $\lambda_{1}=\lambda_{2}=1.064 \mu \mathrm{m}$, the TNCPM regime takes place at $\varphi=48^{\circ}$ and $\theta=43^{\circ}$, and at $\lambda_{1}=\lambda_{2}=3.48 \mu \mathrm{m}$ it occurs in the $x z$ plane $\left(\varphi=0^{\circ}, \theta=54^{\circ}\right)$. Thus, for SHG with the ssf type of interaction, the TNCPM regime can be obtained in the range from 0.774 to $3.48 \mu \mathrm{m}$ with a change in the direction from the $x y$ plane to the $x z$ plane. The results of Figure 1a demonstrate that, in the principal planes $x y, y z$ and $x z$ of the crystal (up to the optical axis), $d_{\mathrm{eff}}=0$, and the results of Figure 11a,c are of no practical value. The maximum conversion efficiency for the ssf type with TNCPM can be obtained at $\lambda_{1}=\lambda_{2}$ of about $3.25 \mu \mathrm{m}$.

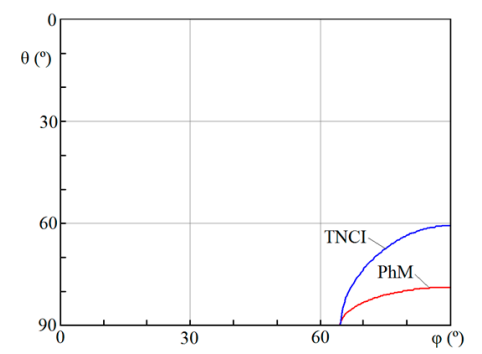

(a) $\lambda_{1}=\lambda_{2}=0.747 \mu \mathrm{m}$

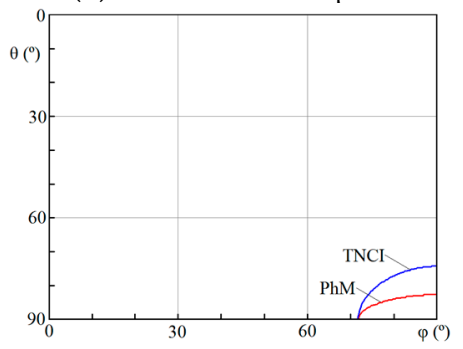

(d) $\lambda_{1}=\lambda_{2}=1.002 \mu \mathrm{m}$

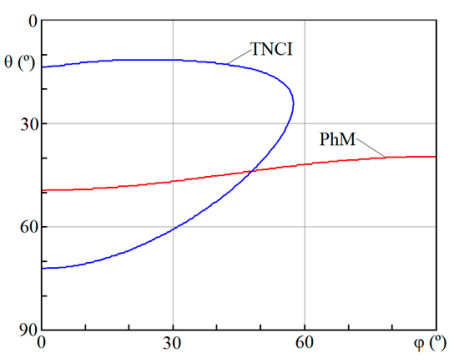

(b) $\lambda_{1}=\lambda_{2}=1.064 \mu \mathrm{m}$

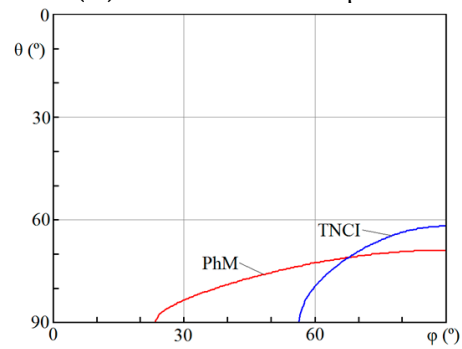

(e) $\lambda_{1}=\lambda_{2}=1.064 \mu \mathrm{m}$

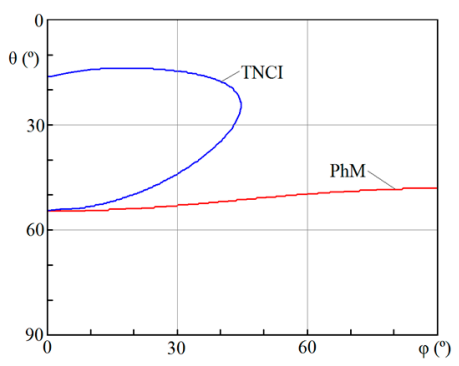

(c) $\lambda_{1}=\lambda_{2}=3.48 \mu \mathrm{m}$

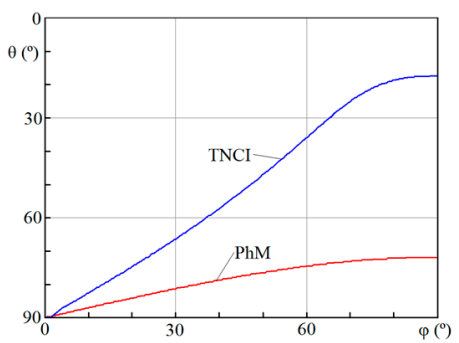

(f) $\lambda_{1}=\lambda_{2}=3.18 \mu \mathrm{m}$

Figure 11. Angular dependencies of PhM and TNCI directions for SHG in KTP crystal at different wavelengths for $(\mathbf{a}-\mathbf{c})$ : ssf, and $(\mathbf{d}-\mathbf{f})$ : sff types of interactions.

For the sff-type interaction, the TNCPM regime can be obtained in the wavelength range $1.002-3.180 \mu \mathrm{m}$. The character of the change in the direction of TNCPM is such that it appears in the $x y$ plane at a wavelength of $1.002 \mu \mathrm{m}\left(\varphi=72^{\circ}, \theta=90^{\circ}\right)$ (Figure 11d). As the wavelength increases, the directions change, but TNCPM with a maximum wavelength does not intersect the main planes of the crystal. The results for the sff type in Figure $1 \mathrm{~b}$ demonstrate that the maximum value of $d_{\text {eff }}$ (along the $x$ axis) cannot be obtained. The value of $F O M_{\mathrm{T}}\left(\lambda_{1}, \lambda_{2}\right)$ is $3-4$ times smaller than the value along the $x$ axis. But at a wavelength of $3.18 \mu \mathrm{m}$ TNCPM takes place along the $x$ axis. In this case, there is TNCPM, angular noncritical phase matching and a maximal value of $d_{\text {eff. The result of }}$ Figure 11 agrees with the experimental data obtained in Refs. [67-72].

For the KTP crystal, the $F O M_{\mathrm{T}}\left(\lambda_{1}, \lambda_{2}\right)$ distributions with TNCPM are shown in Figure 12 for all types of interactions. The region for the existence of phase matching (the wavelength region with phase matching without TNCPM), corresponding to Figure 2, is shown by gray. Here, the phase matching is temperature critical. The distribution from the regions with different levels/color corresponds to the temperature-noncritical phase matching (wavelength region with TNCPM).

A comparison of Figures 2 and 11 for the KTP crystal shows that the values of $F O M\left(\lambda_{1}, \lambda_{2}\right)$ are different for the same combinations of the wavelengths. When these values are equal for the KTP crystal, the TNCPM direction lies in the main plane, where $d_{\text {eff }}$ has a maximum value. In the case of SHG, this takes place for $f_{s f}=s f f$ type phase matching at a wavelength of $3.18 \mu \mathrm{m}$ (Figure 11). 
Additionally, it is possible at different combinations of $\lambda_{1}$ and $\lambda_{2}$. With $F O M_{D}\left(\lambda_{1}, \lambda_{2}\right)$ differs from $F O M_{\mathrm{T}}\left(\lambda_{1}, \lambda_{2}\right)$, the direction of TNCPM has the most common orientation: $90^{\circ}>\theta>0^{\circ}$ and $90^{\circ}>$ $\varphi>0^{\circ}$. In this case, $d_{\text {eff }}$ will be less than the maximum possible value for the selected combination of wavelengths.

The $\operatorname{FOM}_{\mathrm{T}}\left(\lambda_{1}, \lambda_{2}\right)$ distributions, similar to those in Figure 12, are presented for KTA (Figure 13), RTP (Figure 14), RTA (Figure 15), and CTA (Figure 16) crystals. One can see from these figures that only in the KTP and RTP crystals there are directions in the crystal transparency range along which TNCPM is realized. For KTA and RTA crystals, the TNCPM region is much smaller than the phase-matching region. For the CTA crystal, no TNCPM is realized at any combination of wavelengths $\lambda_{1}$ and $\lambda_{2}$.

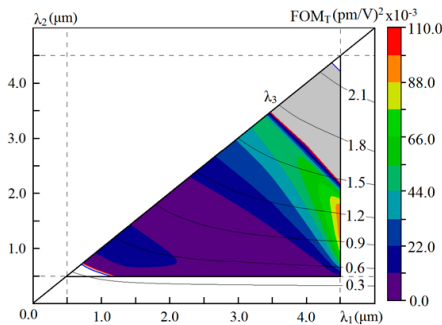

(a) $s s f$

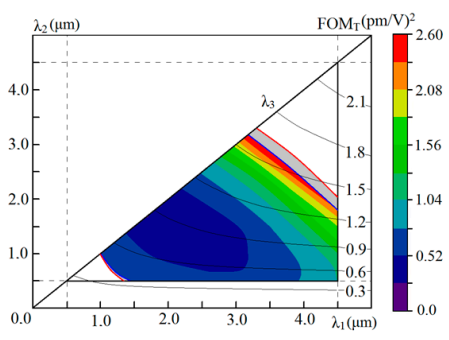

(b) $f s f$

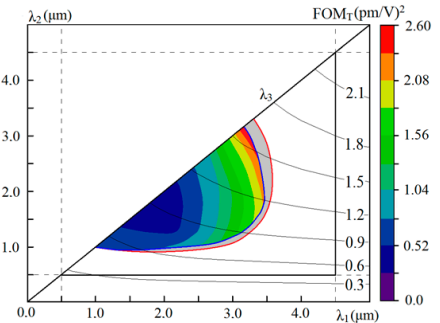

(c) $s f f$

Figure 12. $F O M_{\mathrm{T}}\left(\lambda_{1}, \lambda_{2}\right)$ distributions for KTP crystal for all types of interactions: (a) $s s f$, (b) $f s f$, (c) $s f f$.

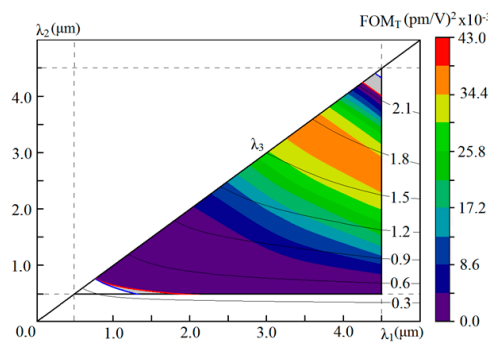

(a) $s s f$

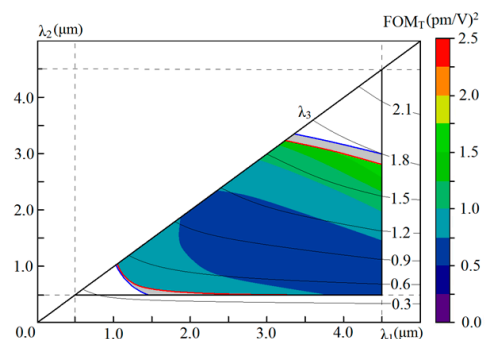

(b) $f s f$

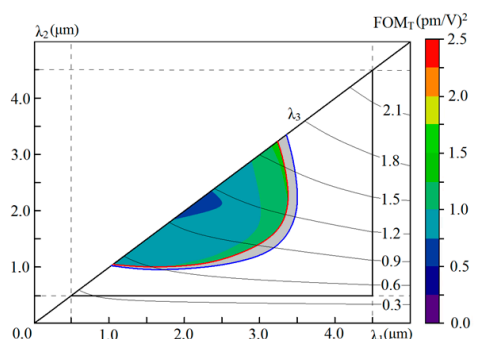

(c) $s f f$

Figure 13. $F O M_{\mathrm{T}}\left(\lambda_{1}, \lambda_{2}\right)$ distributions for RTP crystal for all types of interactions: (a) ssf, (b) $f s f$, (c) sff.

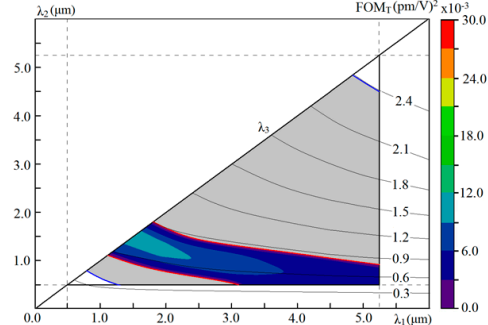

(a) $s s f$

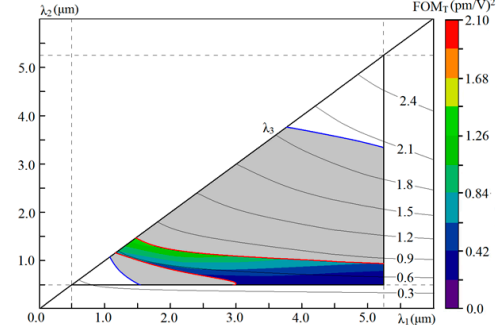

(b) $f s f$

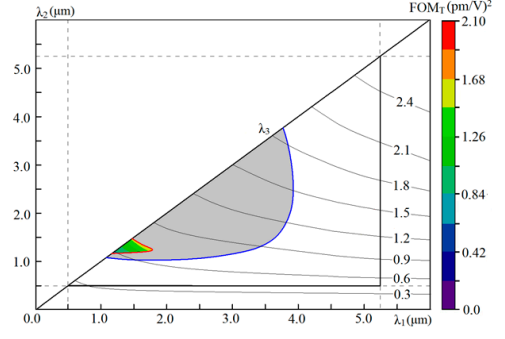

(c) $s f f$

Figure 14. $F O M_{\mathrm{T}}\left(\lambda_{1}, \lambda_{2}\right)$ distributions for KTA crystal for all types of interactions: (a) $s s f,(\mathbf{b}) f s f$, (c) $s f f$.

In analyzing the results of Figures $12-16$, it is necessary to pay attention to one peculiarity. For example, more than 10 papers have been published for the KTP crystal in which the Sellmeier equations $n_{\mathrm{i}}(\lambda)$ are given for the principal values of the refractive indices, and the data are lesser extent, from the values of $n_{\mathrm{i}}(\lambda)$. As noted above, the following data were used to calculate the $F O M_{\mathrm{T}}\left(\lambda_{1}\right.$, $\lambda_{2}$ ) distributions for the KTP crystal (Figure 12): $n_{\mathrm{i}}(\lambda)$ [49], $d n_{\mathrm{i}}(\lambda) / d \mathrm{~T}$ [50]. They give a fairly good agreement with the results of calculations and the experimental data for phase-matching angles, mainly in the visible and near-IR ranges. Additionally, a good agreement was obtained for the temperature widths of phase-matching. A comparison of the experimental results with the TNCPM [70] was carried out using the data for $d n_{\mathrm{i}}(\lambda) / d \mathrm{~T}$ from [50]. As a result, a good agreement was obtained. 
Later, more precise measurements of the parameters were made for the KTP crystal [49]. The obtained data for $n_{\mathrm{i}}(\lambda)$ are in very good agreement with the results of calculations for the phase-matching angles in the crystal transparency range. The data for $d n_{\mathrm{i}}(\lambda) / d \mathrm{~T}$ in Reference [49] give good agreement for the temperature-critical phase matching in the visible-near-IR range. But in the crystal transparency range of the KTP crystal, the FOM $\left(\lambda_{1}, \lambda_{2}\right)$ distributions (see Figure 17) considerably differ from the results of Figure 12. The ranges of wavelengths within which TNCPM is present also differ. Comparison of the results in Figures 12 and 17 raises the problem of refinement of the data on $d n_{\mathrm{i}}(\lambda) / d \mathrm{~T}$ in the KTP crystal transparency range. At the same time, it is necessary to measure the temperature derivatives for refractive indices of the second and higher orders to determine the temperature widths of phase matching [72,73]. Based on this, at present, the reliability of the above results for RTP, KTA, RTA, and CTA crystals cannot be guaranteed (Figures 13-16). Much less research was carried out for these crystals than for the KTP crystal.

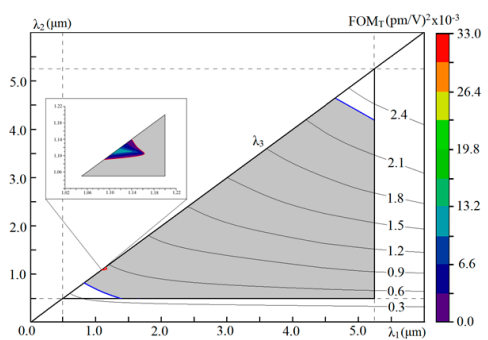

(a) $s s f$

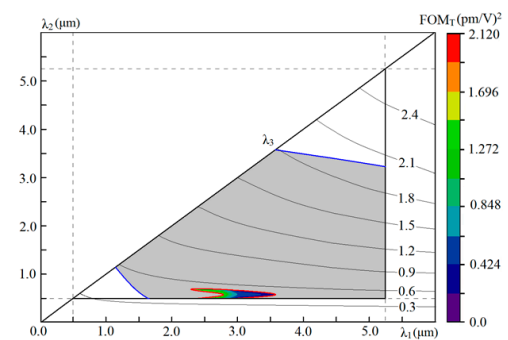

(b) $f s f$

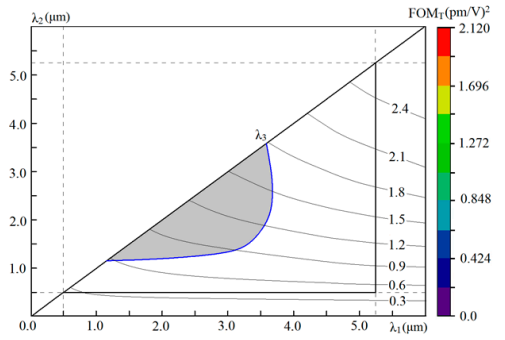

(c) $s f f$

Figure 15. FOMT $\left(\lambda_{1}, \lambda_{2}\right)$ distribution for RTA crystal for all types of interactions: (a) ssf, (b) $f s f$, (c) sff.

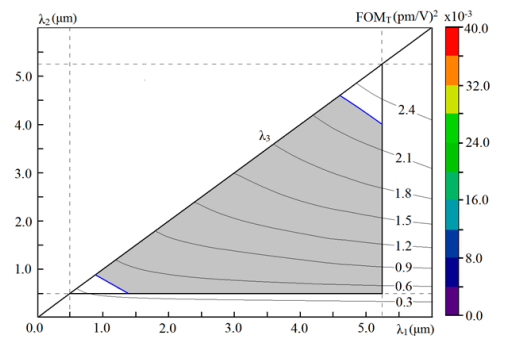

(a) $s s f$

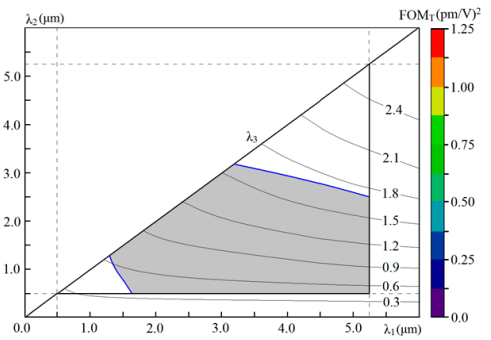

(b) $f s f$

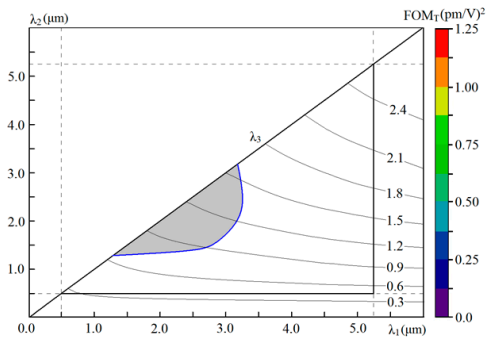

(c) $s f f$

Figure 16. $\mathrm{FOM}_{\mathrm{T}}\left(\lambda_{1}, \lambda_{2}\right)$ distribution for CTA crystal for all types of interactions: (a) $s s f$, (b) $f s f$, (c) $s f f$.

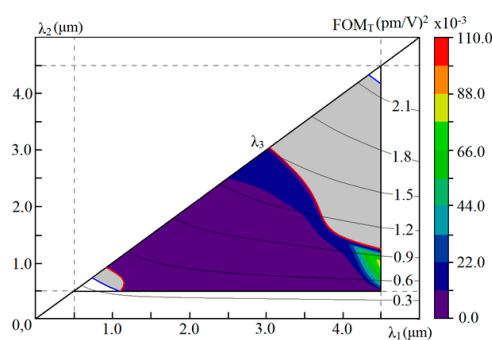

(a) ssf

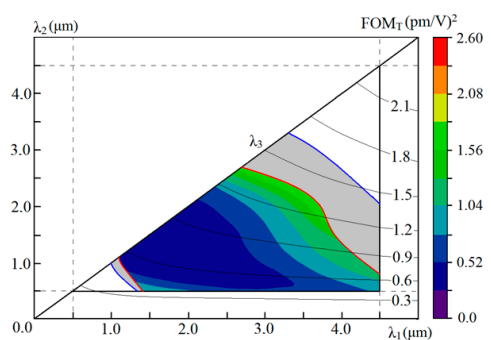

(b) fsf

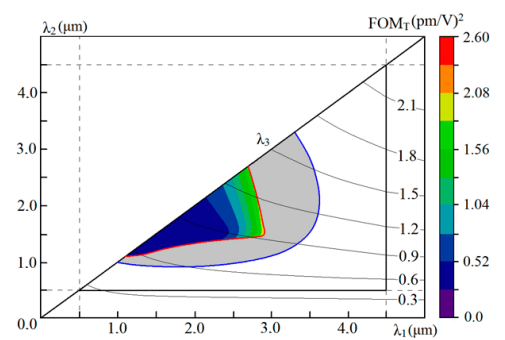

(c) sff

Figure 17. FOM $\mathrm{T}_{\mathrm{T}}\left(\lambda_{1}, \lambda_{2}\right)$ distribution for KTP crystal for all types of interactions with data on $d n_{\mathrm{i}} / d \mathrm{~T}$ from [49]: (a) $s s f$, (b) $f s f$, (c) $s f f$.

Without pretending to rigorous determination of the results (see Figures 12-16) at this stage, it can be formally noted that in the largest wavelength region, the TNCPM regime takes place for phosphate crystals (KTP and RTP). In a much smaller region, the TNCPM is realized for crystals containing arsenic (RTA and KTA). The presence of cesium in the crystal together with arsenic (CTA) 
leads to the fact that the TNCPM regime is absent in the crystal transparency. This is confirmed by the results of Reference [54], in which the temperature width of phase matching did not exceed $11.1^{\circ} \mathrm{C} \cdot \mathrm{cm}$ for different frequency conversion processes in the range $0.532-2.02 \mu \mathrm{m}$. All this requires an appropriate analysis.

\section{Conclusions}

The paper presents the results showing the functional capabilities of the KTP crystal and its isomorphs for nonlinear-optical frequency conversion in the range of their transparency for all types of interactions with maximal value of effective nonlinear coefficient. Combinations of wavelengths are shown, at which angle-, wavelength, and temperature-noncritical phase matching is realized. The boundary of distribution corresponds to angular noncritical phase matching along $y$ axis. Additionally, the obtained results show angular noncritical phase matching along $x$ and $z$ axes. The wavelength noncritical phase matching corresponds to the extremum on distribution.

Realization of temperature noncritical phase matching is represented. This regime can be realized in wide band of wavelengths in some crystals. One can see from obtained results that only in the KTP and RTP crystals there are directions in the crystal transparency range along which TNCPM is realized. For KTA and RTA crystals, the TNCPM region is much smaller than the phase-matching region. For the CTA crystal, no TNCPM is realized at any combination of wavelengths.

Author Contributions: All authors contributed equally to this work.

Funding: This work was supported by the Presidium of RAS (Program I.7 "Modern problems of photonics, the probing of inhomogeneous media and materials").

Conflicts of Interest: The authors declare no conflict of interest.

\section{References}

1. Zumsteg, F.C.; Bierlein, J.D.; Gier, T.E. $\mathrm{K}_{\mathrm{x}} \mathrm{Rb}_{1-\mathrm{x}} \mathrm{TiOPO}_{4}$ : A new nonlinear optical material. J. Appl. Phys. 1976, 47, 4980-4985. [CrossRef]

2. Dezhong, S.; Chaoen, H. A new nonlinear optical crystal KTP. Prog. Cryst. Growth Charact. 1985, 11, $269-274$. [CrossRef]

3. Jacco, J.C. $\mathrm{KTiOPO}_{4}$ (KTP)—Past, present, and future. Proc. SPIE 1988, 968, 93-99.

4. Bierlein, J.D. Potassium titanyl phosphate (KTP): Properties, recent advances and new applications. Proc. SPIE 1989, 1104, 2-12.

5. Bierlein, J.D.; Vanherzeele, H. Potassium titanyl phosphate: Properties and new applications. J. Opt. Soc. Am. B 1989, 6, 622-633. [CrossRef]

6. Stucky, G.D.; Phillips, M.L.F.; Gier, T.E. The potassium titanyl phosphate structure field: A model for new nonlinear optical materials. Chem. Mater. 1989, 1, 492-509. [CrossRef]

7. Cheng, L.K.; Bierlein, J.D. Crystal growth of $\mathrm{KTiOPO}_{4}$ isomorphs from tungstate and molybdate fluxes. J. Cryst. Growth 1991, 110, 697-703. [CrossRef]

8. Thomas, P.A.; Mayo, S.C.; Watts, B.E. Crystal structures of $\mathrm{RbTiOAsO}_{4}, \mathrm{KTiO}\left(\mathrm{P}_{0.58}, \mathrm{As}_{0.42}\right) \mathrm{O}_{4}, \mathrm{RbTiOPO}_{4}$ and $\left(\mathrm{Rb}_{0.465}, \mathrm{~K}_{0.535}\right) \mathrm{TiOPO}_{4}$, and analysis of pseudo symmetry in crystals of the KTiOPO4 family. Acta Cryst. B 1992, 48, 401-407. [CrossRef]

9. Cheng, L.K.; Bierlein, J.D. KTP and isomorphs-Recent progress in device and material development. Ferroelectrics 1993, 142, 209-228. [CrossRef]

10. Cheng, L.K.; Cheng, L.T.; Bierlein, J.D.; Zumsteg, F.C.; Ballman, A.A. Properties of doped and undoped crystals of single domain $\mathrm{KTiOAsO}_{4}$. Appl. Phys. Lett. 1993, 62, 346-348. [CrossRef]

11. Cheng, L.K.; Cheng, L.T.; Galperin, J.; Hotsenpiller, P.A.M.; Bierlein, J.D. Crystal growth and characterization of $\mathrm{KTiOPO}_{4}$ isomorphs from the self-fluxes. J. Cryst. Growth 1994, 137, 107-115. [CrossRef]

12. Wang, J.; Wei, J.; Liu, Y.; Shi, L.; Jiang, M.; Hu, X.; Jiang, S. Growth and properties of some KTP family crystals. Proc. SPIE 1996, 2897, 10-16.

13. Wang, J.; Wei, J.; Liu, Y.; Yin, X.; Hid, X.; Shao, Z.; Jiang, M. A survey of research on KTP and its analogue crystals. Prog. Cryst. Growth Charact. Mater. 2000, 40, 3-15. [CrossRef] 
14. Zhang, K.; Wang, X. Structure sensitive properties of KTP-type crystals. Chin. Sci. Bull. 2001, 46, $2028-2036$.

15. Roth, M.; Tseitlin, M.; Angert, N. Composition-dependent electro-optic and nonlinear optical properties of KTP-family crystals. Opt. Mater. 2006, 28, 71-76. [CrossRef]

16. Sorokina, N.I.; Voronkova, V.I. Structure and properties of crystals in the potassium titanyl phosphate family: A review. Crystallogr. Rep. 2007, 52, 80-93. [CrossRef]

17. Satyanarayan, M.N.; Deepthy, A.; Bhat, H.L. Potassium titanyl phosphate and its isomorphs: Growth, properties, and applications. Crit. Rev. Solid State Mater. Sci. 2010, 24, 103-191. [CrossRef]

18. Phillips, M.L.F.; Harrison, W.T.A.; Gier, T.E.; Stucky, G.D. SHG tuning in the KTP structure field. Proc. SPIE 1989, 1104, 225-231.

19. Thomas, P.A.; Glazer, A.M.; Watts, B.E. Crystal structure and nonlinear optical properties of $\mathrm{KSnOPO}_{4}$ and their comparison with $\mathrm{KTiOPO}_{4}$. Acta Crystallogr. B 1999, 46, 333-343. [CrossRef]

20. Solé, R.; Nikolov, V.; Koseva, I.; Peshev, P.; Ruiz, X.; Zaldo, C.; Martín, M.J.; Aguilo, M.; Díaz, F. Conditions and possibilities for rare-earth doping of $\mathrm{KTiOPO}_{4}$ flux-grown single crystals. Chem. Mater. 1997, 9, 2745-2749. [CrossRef]

21. Gavaldà, J.; Carvajal, J.J.; Mateos, X.; Aguiló, M.; Díaz, F. Dielectric properties of $\mathrm{Yb}^{3+}$ and $\mathrm{Nb}^{5+}$ doped $\mathrm{RbTiOPO}_{4}$ single crystals. J. Appl. Phys. 2012, 111, 034106. [CrossRef]

22. Urenski, P.; Rosenman, G.; Molotskii, M. Polarization reversal and domain anisotropy in flux-grown $\mathrm{KTiOPO}_{4}$ and isomorphic crystals. J. Mater. Res. 2001, 16, 1493-1499. [CrossRef]

23. Shur, V.Y.; Pelegova, E.V.; Akhmatkhanov, A.R.; Baturin, I.S. Periodically poled crystals of KTP family: A review. Ferroelectrics 2016, 496, 49-69. [CrossRef]

24. Laudenbach, F.; Jin, R.-B.; Greganti, C.; Hentschel, M.; Walther, P.; Hübel, H. Numerical Investigation of Photon-Pair Generation in Periodically Poled $\mathrm{MTiOXO}_{4}(\mathrm{M}=\mathrm{K}, \mathrm{Rb}, \mathrm{Cs} ; \mathrm{X}=\mathrm{P}, \mathrm{As})$. Phys. Rev. Appl. 2017, 8, 024035. [CrossRef]

25. Houe, M.; Townsend, P.D. An introduction to methods of periodic poling for second-harmonic generation. J. Phys. D Appl. Phys. 1995, 28, 1747-1763. [CrossRef]

26. Laubacher, D.B.; Guerra, V.L.; Chouinard, M.P.; Liou, J.-Y.; Wyat, P.H. Fabrication and performance of KTP optoelectronic modulators. Proc. SPIE 1988, 993, 80-86.

27. Bierlein, J.D.; Arweiler, C.B. Electro-optic and dielectric properties of $\mathrm{KTiOPO}_{4}$. Appl. Phys. Lett. 1986, 49, 917-919. [CrossRef]

28. Bierlein, J.D.; Ferretti, A.; Brixner, L.H.; Hsu, W.Y. Fabrication and characterization of optical waveguides in $\mathrm{KTiOPO}_{4}$. Appl. Phys. Lett. 1987, 50, 1216-1218. [CrossRef]

29. Noda, K.-I.; Sakamoto, W.; Yogo, T.; Hirano, S.-I. Alkoxy-Derived KTiOPO 4 (KTP) Fibers. J. Am. Ceram. Soc. 1997, 80, 2437-2440. [CrossRef]

30. Butt, M.A.; Pujol, M.C.; Solé, R.; Ródenas, A.; Lifante, G.; Aguiló, M.; Díaz, F.; Khonina, S.N.; Skidanov, R.V.; Verma, P. Fabrication of optical waveguides in $\mathrm{RbTiOPO}_{4}$ single crystals by using different techniques. Proc. SPIE 2016, 9807, 98070C.

31. Karpiński, M.; Radzewicz, C.; Banaszek, K. Experimental characterization of three-wave mixing in a multimode nonlinear $\mathrm{KTiOPO}_{4}$ waveguide. Appl. Phys. Lett. 2009, 94, 181105. [CrossRef]

32. Webjorn, J.; Siala, S.; Nam, D.W.; Waarts, R.G.; Lang, R.J. Visible laser sources based on frequency doubling in nonlinear waveguides. IEEE J. Quant. Electron. 1997, 33, 1673-1686. [CrossRef]

33. Butt, M.A.; Nguyen, H.D.; Ródenas, A.; Romero, C.; Moreno, P.; Aldana, J.R.V.; Aguiló, M.; Solé, R.M.; Pujol, M.C.; Díaz, F. Low-repetition rate femtosecond laser writing of optical waveguides in KTP crystals: analysis of anisotropic refractive index changes. Opt. Express. 2015, 23, 15343-15355. [CrossRef] [PubMed]

34. Bierlein, J.D.; Ferretti, A.; Roelofs, M. KTiOPO 4 (KTP): A new material for optical waveguide applications. Proc. SPIE 1989, 994, 160-168.

35. Cugat, J.; Solé, R.; Carvajal, J.J.; Mateos, X.; Massons, J.; Lifante, G.; Díaz, F.; Aguiló1, M. Channel waveguides on $\mathrm{RbTiOPO}_{4}$ by Cs ${ }^{+}$ion exchange. Opt. Lett. 2013, 38, 323-325. [CrossRef] [PubMed]

36. Butt, M.A.; Pujol, M.C.; Solé, R.; Ródenas, A.; Lifante, G.; Wilkinson, J.S.; Aguiló, M.; Díaz, F. Channel waveguides and Mach-Zehnder structures on $\mathrm{RbTiOPO}_{4}$ by $\mathrm{Cs}^{+}$ion exchange. Opt. Mater. Express. 2015, 5, 1183-1194. [CrossRef] 
37. Butt, M.A.; Solé, R.; Pujol, M.C.; Ródenas, A.; Lifante, G.; Choudary, A.; Murugran, G.S.; Shepherd, D.P.; Wilkinson, J.S.; Aguiló, M.; et al. Fabrication of Y-splitters and Mach-Zehnder Structures on $(\mathrm{Yb}, \mathrm{Nb})$ : $\mathrm{RbTiOPO}_{4} / \mathrm{RbTiOPO}_{4}$ Epitaxial Layers by Reactive Ion Etching. J. Lightwave Technol. 2015, 33, 1863-1871. [CrossRef]

38. Hagerman, M.E.; Poeppelmeier, K.R. Review of the Structure and Processing-Defect-Property Relationships of Potassium Titanyl Phosphate: A Strategy for Novel Thin-Film Photonic Devices. Chem. Mater. 1995, 7, 602-621. [CrossRef]

39. Berger, V. Nonlinear Photonic Crystals. Phys. Rev. Lett. 1998, 81, 4136-4139. [CrossRef]

40. Golcondaa, R.K.; Carvajal, J.J.; Pujol, M.C.; Mateos, X.; Aguiló, M.; Diaz, F.; Vázquez de Aldana, J.R.; Romero, C.; Méndez, C.; Moreno, P.; et al. Fabrication of photonic structures in crystals of the $\mathrm{KTiOPO}_{4}$ family by ultrafast laser ablation. Phys. Procedia 2010, 8, 126-135. [CrossRef]

41. Mounaix, P.; Sarger, L.; Caumes, J.P.; Freysz, E. Characterization of non-linear potassium crystals in the terahertz frequency domain. Opt. Commun. 2004, 242, 631-639. [CrossRef]

42. Kitaeva, G.K. Terahertz generation by means of optical lasers. Laser Phys. Lett. 2008, 5, 559-576. [CrossRef]

43. Antsygin, V.D.; Kaplun, A.B.; Mamrashev, A.A.; Nikolaev, N.A.; Potaturkin, O.I. Terahertz optical properties of potassium titanyl phosphate crystals. Opt. Express 2014, 22, 25436-25443. [CrossRef] [PubMed]

44. Wu, M.-H.; Chiu, Y.-C.; Wang, T.-D.; Zhao, G.; Zukauskas, A.; Laurell, F.; Huang, Y.-C. Terahertz parametric generation and amplification from potassium titanyl phosphate in comparison with lithium niobate and lithium tantalate. Opt. Express 2016, 24, 25964-25973. [CrossRef] [PubMed]

45. Li, Z.; Wang, S.; Wang, M.; Wang, W. Terahertz generation based on cascaded difference frequency generation with periodically-poled $\mathrm{KTiOPO}_{4}$. Curr. Opt. Photonics 2017, 1, 138-142. [CrossRef]

46. Nikogosyan, D.N. Nonlinear Optical Crystals: A Complete Survey; Springer Science \& Business Media: New York, NY, USA, 2005; p. 405.

47. Andreev, Y.M.; Arapov, Y.D.; Grechin, S.G.; Kasyanov, I.V.; Nikolaev, P.P. Functional possibilities of nonlinear crystals for frequency conversion: uniaxial crystals. Quantum Electron. 2016, 46, 33-38. [CrossRef]

48. Andreev, Y.M.; Arapov, Y.D.; Grechin, S.G.; Kasyanov, I.V.; Nikolaev, P.P. Functional possibilities of nonlinear crystals for laser frequency conversion: Biaxial crystals. Quantum Electron. 2016, 46, 995-1001. [CrossRef]

49. Kato, K.; Takaoka, E. Sellmeier and thermo-optic dispersion formulas for KTP. Appl. Opt. 2002, 41, 5040-5044. [CrossRef] [PubMed]

50. Kato, K. Temperature insensitive SHG at 0,531 $\mu \mathrm{m}$ in KTP. IEEE J. Quant. Electron. 1992, 28, $1974-1976$. [CrossRef]

51. Mikami, T.; Okamoto, T.; Kato, K. Sellmeier and thermo-optic dispersion formulas for $\mathrm{RbTiOPO}_{4}$. Opt. Mater. 2009, 31, 1628-1630. [CrossRef]

52. Kato, K.; Takaoka, E.; Umemura, N. Thermo-optic dispersion formula for $\mathrm{RbTiOAsO}_{4}$. Jpn. J. Appl. Phys. 2003, 42, 6420-6423. [CrossRef]

53. Kato, K.; Umemura, N. Sellmeier and thermo-optic dispersion formulas for KTiOAsO4 . In Proceedings of the Conference on Lasers and Electro-Optics, San Jose, CA, USA, 4-9 May 2008; Optical Society of America: Washington, DC, USA, 2008.

54. Mikami1, T.; Okamoto, T.; Kato, K. Sellmeier and thermo-optic dispersion formulas for $\mathrm{CsTiOAsO}_{4}$. J. Appl. Phys. 2011, 109, 023108. [CrossRef]

55. Jacco, J.C.; Loiacono, G.M.; Jaso, M.; Mizell, G.; Greenberg, B. Flux growth and properties of $\mathrm{KTiOPO}_{4}$. J. Cryst. Growth 1984, 70, 484-488. [CrossRef]

56. Gashurov, G.; Belt, R.F. Growth of KTP. In Tunable Solid State Lasers for Remote Sensing, Proceedings of the NASA Conference Stanford University, Stanford, CA, USA, 1-3 October 1984; Byer, R.L., Gustafson, E.K., Trebino, R., Eds.; Springer: New York, NY, USA, 1985; p. 119.

57. Laudise, R.A.; Cava, R.J.; Caporaso, A.J. Phase relations, solubility and growth of potassium titanyl Phosphate, KTP. J. Cryst. Growth 1986, 74, 275-280. [CrossRef]

58. Ballman, A.A.; Brown, H.; Olson, D.H.; Rice, C.E. Growth of potassiuim titanyl phosphate (KTP) from molten tungstate melts. J. Cryst. Growth 1986, 75, 390-394. [CrossRef]

59. Bordui, P.F.; Jacco, J.C.; Loiacono, G.M.; Stolzenberger, R.A.; Zola, J.J. Growth of large single crystals of $\mathrm{KTiOPO}_{4}(\mathrm{KTP})$ from high-temperature solution using heat pipe based furnace system. J. Cryst. Growth 1987, 84, 403-408. [CrossRef] 
60. Voronkova, V.I.; Yanovskii, V.K. Flux growth and properties of the $\mathrm{KTiOPO}_{4}$ family crystals. Neorg. Mater. 1988, 24, 273-277.

61. Sasaki, T.; Miyamoto, A.; Yokotani, A.; Nakai, S. Growth and optical characterization of large potassium titanyl phosphate crystals. J. Cryst. Growth 1993, 128, 950-955. [CrossRef]

62. Orlova, E.I.; Kharitonova, E.P.; Novikova, N.E.; Verin, I.A.; Alekseeva, O.A.; Sorokina, N.I.; Voronkova, V.I. Synthesis, properties, and structure of potassium titanyl phosphate single crystals doped with hafnium. Crystallogr. Rep. 2010, 55, 404-411. [CrossRef]

63. Alford, W.J.; Smith, A.V. Wavelength variation of the second-order nonlinear coefficients of $\mathrm{KNbO}_{3}, \mathrm{KTiOPO}_{4}$, $\mathrm{KTiOAsO}_{4}, \mathrm{LiNbO}_{3}, \mathrm{LiIO}_{3}, \beta-\mathrm{BaB}_{2} \mathrm{O}_{4}, \mathrm{KH}_{2} \mathrm{PO}_{4}$, and $\mathrm{LiB}_{3} \mathrm{O}_{5}$ crystals: A test of Miller wavelength scaling. J. Opt. Soc. Am. B 2001, 18, 524-533. [CrossRef]

64. Pack, M.V.; Armstrong, D.J.; Smith, A.V. Measurement of the $\chi^{(2)}$ tensors of $\mathrm{KTiOPO}_{4}, \mathrm{KTiOAsO}_{4}, \mathrm{RbTiOPO}_{4}$, and $\mathrm{RbTiOAsO}_{4}$ crystals. Appl. Opt. 2004, 43, 3319-3323. [CrossRef] [PubMed]

65. Grechin, S.G.; Grechin, S.S.; Dmitriev, V.G. Complete classification of interaction types for the second-harmonic generation in biaxial nonlinear crystals. Quantum Electron. 2000, 30, 377-386. [CrossRef]

66. Grechin, S.G.; Grechin, S.S. Phase matching and frequency-noncritical interactions upon frequency conversion of femtosecond pulses. Quantum Electron. 2006, 36, 45-50. [CrossRef]

67. Baumert, J.C.; Schellenberg, F.M.; Lenth, W.; Risk, W.P.; Bjorklund, G.C. Generation of blue cw coherent radiation by sum frequency mixing in $\mathrm{KTiOPO}_{4}$. Appl. Phys. Lett. 1987, 51, 2192-2194. [CrossRef]

68. Risk, W.P.; Payne, R.N.; Lenth, W.; Harder, C.; Meier, H. Noncritically phase-matched frequency doubling using $994 \mathrm{~nm}$ dye laser and diode laser radiation in $\mathrm{KTiOPO}_{4}$. Appl. Phys. Lett. 1989, 55, 1179-1181. [CrossRef]

69. Kishimoto, T.; Imamura, K.; Ito, M. Temperature stable SHG of Nd:YAG laser by $\mathrm{KTiOPO}_{4}$. Ann. Meet. Jpn. Soc. Appl. Phys. 1991, 29PB-11.

70. Grechin, S.G.; Dmitriev, V.G.; Dyakov, V.A.; Pryalkin, V.I. Anomalously temperature-noncritical phase matching in frequency conversion in nonlinear crystals. Quantum Electron. 1998, 28, 937-938. [CrossRef]

71. Grechin, S.G.; Dmitriev, V.G.; Dyakov, V.A.; Pryalkin, V.I. Temperature-independent phase matching for second-harmonic generation in a KTP crystal. Quantum Electron. 1999, 29, 77-91. [CrossRef]

72. Grechin, S.G.; Dmitriev, V.G.; Dyakov, V.A.; Pryalkin, V.I. Temperature noncritical processes for propagated in optical crystals laser radiation. Bull. Russ. Acad. Sci. Phys. 2002, 66, 1103-1107.

73. Grechin, S.G.; Dmitriev, V.G.; Dyakov, V.A.; Pryalkin, V.I. Dispersion of the temperature-noncritical frequency conversion and birefringence in biaxial optical crystals. Quantum Electron. 2004, 34, 461-466. [CrossRef] 